\title{
CONTRIBUIÇÕES DA RESOLUÇÃO DE PROBLEMAS NO ÂMBITO DE UMA FORMAÇẤO CONTINUADA COM PROFESSORES DOS ANOS INICIAIS
}

\author{
CONTRIBUTIONS FROM PROBLEM SOLVING IN THE CONTEXT OF A CONTINUING \\ PROFESSIONAL DEVELOPMENT FOR TEACHERS WORKING IN PRIMARY EDUCATION
}

\author{
MORGANA BOZZA 1 \\ LAURETE ZANOL SAUER ${ }^{2}$
}

\section{RESUMO}

0 presente artigo apresenta uma pesquisa, que buscou verificar como a formação continuada em Matemática pode contribuir para a prática pedagógica do professor. Para tanto foi promovido um curso de extensão para professores, que estavam atuando nos anos iniciais do Ensino Fundamental, na rede municipal da cidade de Flores da Cunha - RS. 0 convite para a formação foi enviado, juntamente com um questionário eletrônico que incluía uma pergunta sobre conteúdos de interesse. Os 36 professores respondentes elegeram a resolução de problemas como tema da formação, considerando as dificuldades dos estudantes ao lidarem com essa metodologia. Assim sendo, o curso foi planejado, envolvendo atividades que proporcionaram momentos de reflexão e discussão sobre a resolução de problemas, além de teorias e práticas pedagógicas. A formação continuada foi exitosa, com resultados que evidenciaram segurança progressiva dos professores, em suas ações didático-pedagógicas o que, conforme depoimentos, repercutiu positivamente na aprendizagem dos estudantes.

Palavras-chave: Formação continuada. Professores dos anos iniciais. Resolução de problemas.

\section{ABSTRACT}

This article presents a research that sought to verify how continuing education in Mathematics can contribute to the pedagogical practice of the teacher. To this end, an extension course was promoted for teachers, who were working in primary education, in the municipal network of the city of Flores da Cunha - RS. The training invitation was sent, along with an electronic questionnaire that included a question about content of interest. The 36 respondent teachers chose problem solving as the theme of the training, considering the difficulties of students when dealing with this methodology. Therefore, the course was planned, involving activities that provided moments of reflection and discussion on problem solving, as well as pedagogical theories and practices. Continuing education was successful, with 16 participating teachers, with results that showed progressive security in their didactic-pedagogical actions, which, according to testimonies, had a positive impact on student learning.

Keywords: Continuous formation. Teachers working in primary education. Solving problems.

\footnotetext{
1 Mestra em Ensino de Ciências e Matemática pela Universidade de Caxias do Sul(UCS). Especialista em Gestão Escolar, graduada em Licenciatura Plena em Matemática e Pedagogia, também pela Universidade de Caxias do Sul. Professora dos anos iniciais e de Matemática (anos finais) da rede municipal de Caxias do Sul ede Flores da Cunha, respectivamente. E-mail: mbozza@ucs.br. Orcid: https://orcid.org/0000-0002-7586-7202 2 Doutora em Informática na Educação. Universidade Federal do Rio Grande do Sul (UFRGS). Professora na Universidade de Caxias do Sul (UCS). Izsauer@ucs.br. Orcid: https://orcid.org/0000-0002-8793-5559.
} 


\section{INTRODUÇÃO}

A preocupação com 0 ensino de Matemática no Brasil, vivenciada em diferentes realidades educacionais, tem sido tema de discussões, estudos e pesquisas. Segundo Pacheco e Andreis (2018, p. 2), "há muito tempo, se constata certo descontentamento em torno da aprendizagem em Matemática, por parte dos alunos, e do ensino, por parte dos professores, situação identificada pelos órgãos competentes, responsáveis por avaliações nacionais e internacionais (...)". Diferentes avaliações e pesquisas realizadas, contando com a colaboração da comunidade matemática e com relatos de professores que atuam no ensino básico, em diferentes regiões brasileiras, têm mapeado problemas a serem enfrentados, como, por exemplo, o baixo nível de conhecimento matemático de muitos brasileiros. Estes problemas persistem, constituem uma preocupação evidente e merecem ser analisados, a fim de se elaborar um diagnóstico que embase possíveis soluções.

0 estudo das possíveis causas das dificuldades de aprendizagem nesse componente curricular, que podem estar relacionadas a vários fatores envolvendo 0 aluno, 0 professor, a família e a escola, pode auxiliar na prática docente, pois possibilita ao professor fazer inferências mais acertadas, tornando suas aulas mais motivadoras, eficientes e eficazes. (PACHECO; ANDREIS, 2018, p. 2).

Com efeito, a baixa qualidade da aprendizagem de Matemática, em tantos casos, não está presente apenas no espaço escolar ou nas avaliações externas realizadas por programas específicos, tais como 0 Indicador Nacional de Alfabetismo Funcional (Inaf) ${ }^{3}$, o Sistema Nacional de Avaliação da Educação Básica (SAEB) ${ }^{4}$, o Programa Internacional de Avaliação de Estudantes (PISA) ${ }^{5}$ e 0 Sistema de Avaliação do Rendimento Escolar do Rio Grande do Sul (SAERS) ${ }^{6}$, dentre outros, mas também pode ser percebida no cotidiano, no dia a dia das pessoas, nas mais variadas situações.

Godoy e Santos (2012) indicam algumas metas para a Educação Matemática, relacionadas com necessidades da sociedade atual, quais sejam: proporcionar ao indivíduo a competência matemática que Ihe cabe; prepará-lo para a vida adulta; estimular a reflexão sobre a importância da Matemática na vida cotidiana e na sociedade; desenvolver a habilidade de resolução de problemas, utilizando modelos matemáticos; desenvolver a capacidade de raciocinar e, ainda, proporcionar o estabelecimento de relações com outras áreas do conhecimento.

Contudo, como atingir tais metas? Como ensinar Matemática de forma que seus conceitos sejam significativos para os estudantes? De que forma o conteúdo escolar pode ser relacionado à vida cotidiana dos estudantes? Como colaborar para o desenvolvimento do sujeito contemplando diferentes habilidades? Não existem respostas simples para tais questionamentos, alguns dos quais

\footnotetext{
3 Pesquisa realizada pelo Instituto Paulo Montenegro e a ONG Ação Educativa, com apoio do Instituto Brasileiro de Opinião Pública e Estatística (Ibope). Objetiva mensurar o nível de alfabetismo da população brasileira entre 15 e 64 anos, avaliando habilidades de leitura, escrita e Matemática. Disponível em: <https://ipm.org.br/inaf>. Acesso em: 20 out. 2020.

4 Instituído em 1990, é composto por um conjunto de avaliações com o objetivo de diagnosticar a educação brasileira. Realizado a cada dois anos. Disponível em: <https://www.gov.br/inep/pt-br/areas-de-atuacao/avaliacao-e-exames-educacionais/saeb >. Acesso em: 20 out. 2020. 5 É coordenado em nível mundial pela Organização para Cooperação e Desenvolvimento Econômico (OCDE) e, em nível nacional, pelo Instituto Nacional de Estudos e Pesquisas Educacionais Anísio Teixeira (Inep). Objetiva produzir indicadores sobre a qualidade da educação nos países participantes. As avaliações acontecem a cada três anos e abrangem três áreas do conhecimento (Língua Portuguesa, Matemática e Ciências). Disponível em: <https://www.gov.br/inep/pt-br/areas-de-atuacao/avaliacao-e-exames-educacionais/pisa >. Acesso em: 20. out. 2020.

6 Avaliação realizada no Estado do Rio Grande do Sul para todos os estabelecimentos da rede pública de ensino. Objetiva produzir informações para dar suporte a ações destinadas à melhoria do ensino e aprendizagem, identificando potencialidades e limitações para redefinir ações e estratégias de apoio a situações de menor desempenho. Disponível em: <http://www.saers.caedufjf.net>. Acesso em: 20 out. 2020.
} 
sequer podem ser respondidos. 0 valor da Matemática está em sua utilidade para a vida em sociedade, mas ainda é preciso "descobrir" caminhos para a mudança do cenário educacional atual. Por isso se faz necessário refletir e discutir em conjunto (professores, demais profissionais da educação, pais, alunos, gestores), buscando alterações no panorama educacional atual, que proporcionem aos estudantes condições para aprender e desenvolver-se.

Segundo Freire (1996), a aprendizagem é um processo constante, tanto para o estudante quanto para o professor, acontecendo nas diferentes etapas da vida, em diferentes locais e por meio do contato com diversas pessoas.

Damazio (2008) afirma que o professor é visto como um sujeito que aprende continuamente. No processo de sua formação, o professor precisa ter consciência de que o conhecimento está também em constante transformação e criação e, assim, sua formação continuará, pois, com a construção de novos conhecimentos, o professor pode manter-se atualizado, aprimorando suas ações pedagógicas. Ainda, para este autor, a reflexão sobre a prática pedagógica deve iniciar pelo entendimento do que seja o conhecimento, "o conhecimento do conteúdo e todos aqueles referentes à prática docente e profissional, obtidos no processo educativo de formação de professores." (DAMAZIO, 2008, p. 11). 0 autor afirma que a profissão de professor exige conhecimentos pedagógicos que, muitas vezes, são esquecidos na formação inicial ou são desconsiderados e dão lugar aos conteúdos disciplinares.

Conforme afirma Silva (2011, p. 3), “o termo 'formação contínua' veio tomando corpo no meio educacional a partir das ideias de professores como sujeitos inacabados, em contínuo processo de mudança e transformação". Assim, pode-se compreender a formação continuada como o processo permanente de busca, no qual o professor aperfeiçoa seus saberes profissionais, também construídos na formação inicial. Entretanto, não pode permanecer amarrado ao passado, mas, sim, encarar as novas exigências profissionais, buscando alcançar o objetivo maior de sua profissão: intervir com qualidade visando à aprendizagem dos estudantes.

A formação continuada possibilita ao professor a reflexão e a transformação de sua prática, inclusive permitindo a mudança de paradigmas presentes na escola, os quais têm distanciado o interesse dos estudantes. Chimentão assim justifica a importância da formação continuada:

A nosso ver, a formação continuada passa a ser um dos pré-requisitos básicos para a transformação do professor, pois é através do estudo, da pesquisa, da reflexão, do constante contato com novas concepções, proporcionado pelos programas de formação continuada, que é possível a mudança. Fica mais difícil de o professor mudar seu modo de pensar o fazer pedagógico se ele não tiver a oportunidade de vivenciar novas experiências, novas pesquisas, novas formas de ver e pensar a escola. (CHIMENTÃO, 2009, p. 3).

Ainda conforme Silva (2011, p. 1), "a formação continuada não é uma prática nova, ela existe desde longos tempos, orientando a preparação dos professores e sua prática. É algo vivenciado pelos homens como maneira de se reconstruírem, modificarem". A autora ressalta que o termo continuada refere-se ao processo como sequência, algo ininterrupto, que aprimora a formação inicial, "ações que possam auxiliar o profissional no seu desempenho profissional." (SILVA, 2011, p. 2). Ou seja, trata-se da busca por estratégias inovadoras que auxiliam no desenvolvimento de uma prática pedagógica mais qualificada, que implica positivamente na aprendizagem do estudante, 
propiciando que desenvolva diferentes habilidades (pesquisar, opinar, ser autônomo) que correspondam à sua formação como sujeito integral. E recomenda:

faz-se necessário rever como ocorre a formação continuada dos professores e colocá-los no lugar de agentes da própria formação, não por obrigação, mas por desejo, vontade e até, quem sabe, por necessidade, uma vez que ninguém nasce professor, faz-se professor. Aprende-se a ser professor. E o processo de aprender está intimamente ligado ao desejo. (SILVA, 2011, p. 3).

A sociedade atual apresenta-se com muitas mudanças, as quais acontecem com grande velocidade, influenciando no contexto educacional. Dessa forma, "a formação continuada de professores, ou de qualquer profissional, surge como alternativa para acompanhar este ritmo." (LIMA; SILVA NETO, 2012, p. 7). Os autores citam o trabalho de Fiorentini e Lorenzato (2009), que analisaram mais de cento e vinte dissertações e teses produzidas nos mais de trinta Programas de Pós-Graduação da década de 90, apontando como relevante o número de investigações sobre a problemática da formação de professores de Matemática, desenvolvidas nas universidades brasileiras.

Perante 0 exposto, o foco principal da pesquisa aqui relatada foi investigar os efeitos da formação continuada na trajetória profissional e na prática pedagógica dos professores que atuam nos anos iniciais do Ensino Fundamental (10 ao 50 ano). A mesma integra a dissertação de Mestrado de uma das autoras (BOZZA, 2017), cujas principais atividades relacionadas ao curso de formação continuada são aqui relatadas. Para tanto, como atividade prévia, foi apresentada uma proposta de curso de extensão, aos professores da rede municipal do município de Flores da Cunha, acompanhada de um questionário, no qual uma das perguntas solicitou que optassem por conteúdos de interesse, dentre os que foram apresentados como possibilidades. Com o retorno recebido, além da manifestação de interesse pelo curso, os professores elegeram a resolução de problemas como o tema a ser abordado. Diante destas considerações, o problema de pesquisa gerou o seguinte questionamento:

Qual a contribuição de um curso de formação continuada, com enfoque na resolução de problemas matemáticos, para a prática pedagógica do professor dos anos iniciais do Ensino Fundamental? Com o principal objetivo de responder a esta questão, teve-se como objetivos específicos:

- conhecer como professores, que atuam nos anos iniciais do Ensino Fundamental, percebem a qualidade de sua formação (inicial e/ou continuada), no que tange à área de Matemática;

- planejar formas de auxiliar na melhoria e no aprimoramento da prática pedagógica no ensino de Matemática, partindo da realidade de professores dos anos iniciais;

- promover um curso de formação continuada para professores que atuam de $1^{0}$ ao $5^{\circ}$ ano do Ensino Fundamental, de forma a contribuir para a qualificação do ensino de Matemática, nesta etapa escolar;

- analisar e avaliar 0 curso promovido, em relação à sua contribuição com a qualidade da prática pedagógica do professor de Matemática, bem como das aprendizagens promovidas.

Assim sendo, o presente artigo está organizado de forma que, na próxima seção, apresentam-se os procedimentos metodológicos utilizados na realização da pesquisa: o percurso metodológico escolhido, o contexto da pesquisa, os instrumentos utilizados para construção dos dados e sua análise, os quais embasaram as intervenções pedagógicas descritas, que resultaram no curso de formação continuada ofertado. Na sequência, são apresentados os principais momentos do curso, 
acompanhados de discussão e análise de resultados, construída a partir da Análise de Conteúdo proposta por Moraes (1999) e, por fim, possíveis conclusões e considerações finais.

\section{O PERCURSO METODOLÓGICO}

0 estudo de campo foi desenvolvido no Município de Flores da Cunha, localizado no Rio Grande do Sul. A "Terra do Galo", como é conhecida, conta com oito escolas municipais de Ensino Fundamental, distribuídas no meio urbano e rural. Duas escolas oferecem turno integral, em uma modalidade, como complementação da carga horária legal, exigida pela lei; e uma escola atende à Educação de Jovens e Adultos (EJA). A rede municipal possui 2.912 alunos matriculados (considerando a Educação Infantil, o Ensino Fundamental, turno integral e EJA) e totaliza 235 professores efetivos, sendo 49 professores em exercício nos anos iniciais do Ensino Fundamental (1ํㅜㅇ a $5^{\circ}$ ano), sem considerar os professores que trabalham com o turno integral.

0 Município oferta anualmente diversos cursos de formação para os professores, sendo a participação facultativa. Os cursos geralmente acontecem no turno vespertino ou noite, durante os dias de semana, ou nos sábados pela manhã. São gratuitos e certificados pela própria Secretaria Municipal de Educação, Cultura e Desporto (SMECD). Tais formações abordam assuntos diversos, 0 que determina o público-alvo (professores dos anos iniciais e/ou anos finais).

Com a definição do problema de pesquisa, delimitou-se o público-alvo e a perspectiva de oferecer uma formação continuada, na rede municipal de Flores da Cunha, para os professores que atuam nos anos iniciais do Ensino Fundamental. Iniciou-se com o convite e questionário, que foram encaminhados às escolas. Com base no levantamento de dados, construiu-se uma proposta da formação continuada, a partir das necessidades indicadas nas respostas dos professores que responderam o questionário.

Dos 49 professores dos anos iniciais (10 ao $5^{\circ}$ ano) do Ensino Fundamental da rede municipal citada, que receberam o questionário, por meio eletrônico, com questões abertas e fechadas, 36 professores retornaram com suas respostas. Estas auxiliaram na compreensão de como acontecem as formações no Município e quais as dificuldades percebidas no ensino e na aprendizagem de Matemática. Os dados foram considerados para o planejamento do curso de formação continuada, com o objetivo de qualificar as ações pedagógicas, a partir das necessidades levantadas pelos professores respondentes.

Quanto ao perfil, tais professores são, na quase totalidade, do sexo feminino e têm idade de 30 anos ou mais. A maioria, $64 \%$ dos professores, reside no Município de Flores da Cunha. Dos demais, a maior parte reside em Caxias do Sul, e vão até o município vizinho para trabalhar; um número expressivo, chegando a $31 \%$. Quanto ao grau de escolaridade, 83\% cursaram o Magistério e 100\% dos professores possuem curso superior. 0 curso de Pedagogia foi cursado por $61 \%$ dos professores. $72 \%$ dos professores já concluíram um ou mais cursos de especialização e $6 \%$ estão cursando. Sendo assim, aproximadamente $78 \%$ dos professores buscaram complementar sua formação em cursos de pós-graduação.

A carga horária de trabalho apresenta que $42 \%$ deles lecionam cerca de 40 horas semanais, e outros $19 \%$ atuam como professor, durante 20 horas semanais e possuem mais uma atividade profissional (oficineiro, coordenador pedagógico, vice-diretor ou secretária) durante outras 20 horas semanais. Logo, $61 \%$ dos entrevistados trabalham 40 horas semanais. Apenas $36 \%$ dos entrevistados atuam somente 20 horas semanais como professores e um entrevistado atua 30 horas semanais.

Grande parte dos professores possui experiência com docência nos anos iniciais, dado que $67 \%$ deles têm mais de 11 anos de trabalho neste nível de ensino. 
Dentre os professores que responderam o questionário, $75 \%$ afirmaram que já participaram de formações continuadas (cursos, palestras, seminários, congressos, workshops, dentre outros) na área de Matemática, sendo que 25\% não tiveram interesse ou oportunidade de participar.

As formações continuadas cursadas pelos participantes foram consideradas proveitosas, já que $96 \%$ afirmaram que contribuíram muito ou em parte para o aprimoramento de suas práticas pedagógicas.

Os professores foram questionados sobre alguns aspectos da formação continuada que estava sendo oferecida, e tiveram a oportunidade de escolher conforme suas necessidades e possibilidades de participação, sobre o perfil do curso de formação (horário dos encontros, carga horária, formato dos encontros, frequência dos encontros, dentre outros).

Em relação aos conteúdos matemáticos que poderiam ser tema da formação, foi apresentada uma lista de tópicos, com a possibilidade de escolherem mais de um, conforme mostra a Tabela 1, com a referida questão, como foi apresentada no questionário, já acompanhada dos percentuais de respostas.

Tabela 1 - Questão referente aos possíveis tópicos a serem abordados no curso.

Considerando os conteúdos matemáticos listados, que assuntos você gostaria de saber mais, de forma a se sentir mais capacitado para atuar em sala de aula? Assinale todos os que você gostaria de estudar mais.

\begin{tabular}{cl}
\hline Percentual & \multicolumn{1}{c}{ Tópico } \\
\hline$(23 \%)$ & Geometria(figuras planas e espaciais, ângulos, localização, elementos das figuras) \\
$(12 \%)$ & $\begin{array}{l}\text { Grandezas e medidas (comprimento, capacidade, massa, tempo, sistema monetário, } \\
\text { perímetro, temperatura, volume) }\end{array}$ \\
$(19 \%)$ & Estatística e probabilidade (dados, tabelas, gráficos) \\
$(33 \%)$ & $\begin{array}{l}\text { Números e operações (quatro operações, problemas matemáticos, representação fracio- } \\
\text { nária, representação decimal, porcentagem) }\end{array}$ \\
$(9 \%)$ & Álgebra e funções (sequências numéricas ou de padrões) \\
\hline$(4 \%)$ & Outros? Quais? \\
\hline
\end{tabular}

Fonte: elaboração das autoras

A justificativa para as opções apontadas, foi dada em resposta à pergunta seguinte, do questionário, como mostra a Tabela 2, com a transcrição da questão apresentada.

Tabela 2 - Justificativas para a escolha do tema a ser abordado no Curso

Por favor, comente sobre sua(s) escolha(s) do tema a ser abordado: dificuldades sobre o(s) assunto(s), curiosidade(s) sobre o(s) tema(s) ou outro comentário que justifique a(s) alternativa(s) assinalada(s).

\begin{tabular}{cl}
\hline Percentual & \\
\hline$(17 \%)$ & Preocupação com a aprendizagem dos estudantes \\
$(34 \%)$ & $\begin{array}{l}\text { Oportunidade de conhecer novas estratégias de ensino, que envolvam atividades práticas } \\
\text { (jogos, materiais concretos, etc.) }\end{array}$ \\
$(19 \%)$ & Dificuldade própria, sendo a possibilidade de ampliar seu conhecimento \\
$(22 \%)$ & Forma de discutir como aproximar a Matemática do dia a dia e do cotidiano do estudante \\
$(8 \%)$ & Outros/Não respondeu \\
\hline
\end{tabular}

Fonte: Elaboração das autoras 
Os apontamentos que constam na Tabela 2 são percepções dos próprios professores que os destacaram como necessidades identificadas em seu cotidiano profissional. Desta forma, percebe-se que há interesse na participação em uma formação continuada, visando à própria qualificação profissional, bem como para qualificar a aprendizagem dos estudantes. Com efeito, o professor precisa avaliar constantemente sua atuação, revendo e aprimorando sua prática pedagógica.

Sobre as maiores dificuldades dos estudantes, os entrevistados apontaram as que consideram principais: $55 \%$ acreditam que seja o raciocínio lógico, abstração e interpretação e $42 \%$ indicaram dificuldades nos cálculos (quatro operações e a tabuada). Apenas um professor, o que corresponde a aproximadamente $3 \%$, não indicou sua percepção.

De posse de todas estas informações planejou-se o curso intitulado "Formação Continuada em Matemática: estratégias didáticas para resolução de problemas", visando atender as necessidades apontadas pelos participantes, professores do $1^{\circ}$ ao $5^{\circ}$ ano do Ensino Fundamental.

Na próxima seção, apresenta-se o referido curso, bem como a discussão de resultados obtidos.

\section{O CURSO DE FORMAÇÃO CONTINUADA: RESULTADOS E DISCUSSÃO}

Conforme mencionado na Introdução, iniciou-se a divulgação do curso, através de correspondência eletrônica para todas as escolas municipais de Flores da Cunha e os interessados realizaram a inscrição de forma virtual (e-mail). Foram recebidas 16 inscrições, ou seja, 33\% do total de professores da SMECD, confirmaram interesse em participar. Os seis encontros presenciais da formação foram quinzenais e aconteceram no turno vespertino/noite de quintas-feiras, no espaço de uma escola municipal. Em cada um dos encontros foram solicitadas atividades para serem realizadas a distância, totalizando, assim, a carga horária de 40 horas/aula.

Em todos os encontros, abordou-se uma dinâmica, um desafio ou uma situação-problema, com o objetivo de motivar os participantes, além de servir como sugestão de atividade prática a ser explorada pelos professores com os próprios estudantes. Na Tabela 3 é apresentada uma lista das principais atividades promovidas, que envolveram ações e discussões pedagógicas, bem como conteúdos matemáticos e resolução de problemas.

Tabela 3 - Principais atividades promovidas no curso

\begin{tabular}{l}
\hline \multicolumn{1}{c}{ Atividade } \\
\hline Dinâmicas para integração e desenvolvimento do raciocínio lógico. \\
Reflexões e discussões a partir de leituras de textos selecionados e apresentados através de slides. \\
Estudos teóricos sobre: resolução de problemas matemáticos envolvendo os conteúdos selecionados na \\
Tabela 1, planejamento, avaliação e o papel do erro na aprendizagem. \\
Resolução de problemas matemáticos e desafios lógicos. \\
Exploração de jogos concretos e virtuais. \\
Criação de materiais pedagógicos para sala de aula, considerando a realidade de cada participante. \\
Exploração de sites com conteúdos matemáticos para conhecer possibilidades de materiais para aplicar \\
em sala de aula.
\end{tabular}

Fonte: Elaboração das autoras 
Cabe ressaltar que $81 \%$ dos professores inscritos concluíram o curso com frequência superior a $80 \%$ e receberam certificado expedido pela SMECD.

Os dados apresentados a seguir são resultantes da participação dos professores na formação continuada, por meio da realização das atividades promovidas e discussões relacionadas, bem como dos depoimentos oriundos de respostas registradas e das participações nas referidas atividades. De forma oral ou escrita, os participantes apresentaram seus conhecimentos sobre a resolução de problemas no ensino de Matemática; sobre as expectativas da formação realizada; sobre saberes e experiências vivenciadas durante a formação continuada e com demonstrações de reflexões pessoais sobre suas práticas pedagógicas. "Revelam percepções, manifestam expectativas, relatam angústias, apresentam incertezas e celebram avanços. Outrossim, expressam a experiência de ser professor na atualidade, tendo que conviver com os mais diversos tipos de situações tanto positivas como negativas da sala de aula [...]"(KÖNIG, 2013, p. 132).

A metodologia utilizada para analisar os dados foi a Análise de Conteúdo, de acordo com as ideias de Moraes (1999), a qual tem, como parte do processo, a criação de categorias. As categorias não são únicas, são singulares e resultam da visão do pesquisador; logo, outro pesquisador poderia sugerir categorias distintas, fato justificado pelo caráter qualitativo da pesquisa, pois permite apresentar 0 olhar do pesquisador durante 0 processo desenvolvido. Nesta pesquisa foram identificadas as categorias:

- Categoria 1 - Expectativas;

- Categoria 2 - Ensinar exige reflexão e pesquisa;

- Categoria 3 - Ensinando a resolver problemas;

- Categoria 4 - Contribuições da formação continuada na prática pedagógica.

Como suporte para análise dos dados, buscou-se apoio em referenciais teóricos sobre os temas: formação continuada de professores e resolução de problemas matemáticos.

\section{Categoria 1: Expectativas}

Esta categoria originou-se de um dos objetivos específicos da pesquisa, que buscava conhecer como os professores, atuantes nos anos iniciais do Ensino Fundamental (10 ao $5^{\circ}$ ano), percebiam a qualidade de suas formações (inicial e/ou continuada), principalmente na área matemática.

Dentre os professores que participaram da formação, 84\% cursaram Pedagogia como formação inicial, os demais estão licenciados em outras áreas (Geografia e Letras), observando-se, assim, que nenhum dos participantes teve formação inicial em Matemática. Assim sendo, nesta categoria, foram registradas as expectativas dos professores em relação à Matemática, apontando motivos pelos quais se sentiram estimulados a participar da formação continuada. Dentre os aspectos apontados, percebeu-se a preocupação dos professores em buscar novas abordagens (estratégias) para 0 trabalho de sala de aula, aprofundando seus conhecimentos, para tornar os conteúdos matemáticos mais significativos, interessantes e prazerosos aos estudantes. Os participantes ressaltam ainda a necessidade de conhecer novos recursos pedagógicos, como materiais concretos e atividades práticas. Em algumas de suas respostas ${ }^{7}$, revelaram intenções, dentre as quais as que se destacam na Tabela 4.

7 0s depoimentos dos participantes foram organizados de forma a não revelar suas identidades. Para isso, utilizou-se a união de um número, que representa 0 encontro da formação continuada que o participante realizou tal reflexão, seguido de uma letra para distinguir os participantes. As letras utilizadas não representam sempre o mesmo participante, pois em alguns encontros as atividades foram respondidas de forma anônima. 
Tabela 4 - Expectativas.

\begin{tabular}{cl}
\hline Participante & \multicolumn{1}{c}{ Expectativas } \\
\hline (1E) & $\begin{array}{l}\text { Refletir a minha prática e que isso se transforme em contribuições para planejamento e, } \\
\text { assim, melhorar a aprendizagem dos alunos. }\end{array}$ \\
(1J) & $\begin{array}{l}\text { Ampliar e enriquecer a minha prática docente de modo a facilitar a compreensão e o enten- } \\
\text { dimento da resolução de situações-problema. }\end{array}$ \\
\hline
\end{tabular}

Fonte: Elaboração das autoras

As respostas indicam a preocupação dos professores em contribuir nos processos de ensino e de aprendizagem de Matemática. A formação continuada de professores, de acordo com Garcia (2011), está ligada à qualificação do ensino, sendo o professor um agente de mudança; para isso, precisa ser desenvolvida através de atividades que permitam aos participantes questionar, investigar e refletir. Tais ações foram desenvolvidas na formação continuada planejada e realizada, voltada para a mudanças na prática profissional e integrando teoria e prática, formação e ação.

Os participantes puderam apontar conteúdos matemáticos dos anos iniciais que gostariam de saber mais, para sentirem-se melhor capacitados a atuar em sala de aula. Os conteúdos citados, conforme já referidos, foram abordados, com ênfase na metodologia de resolução de problemas, 0 que também entende-se estar de acordo com suas expectativas.

Deste modo, a formação continuada desenvolvida considerou a prática docente dos professores participantes como objeto de estudo e reflexão, permitindo aos sujeitos refletir sobre suas necessidades reais, debater e desenvolver estratégias para qualificar suas ações pedagógicas e, em seguida, refletir sobre as ações realizadas, destacando pontos que foram válidos e quais ainda poderiam melhorar.

\section{Categoria 2: Ensinar exige reflexão e pesquisa}

A realidade educacional enfrentada pelos professores da educação básica (anos iniciais) foi o ponto de partida para pensar formas de qualificar a prática desenvolvida por estes profissionais da educação, na área de Matemática, conforme sinalizado nos objetivos deste trabalho, pois se faz necessário "ouvir" estes profissionais. Desta forma, esta categoria está relacionada ao contexto de atuação dos professores participantes para assim planejar ações que qualifiquem a aplicação de problemas matemáticos em sala de aula.

Os professores foram então questionados sobre quais as facilidades e dificuldades que a turma em que atuavam apresentava, ao resolver problemas matemáticos: $54 \%$ afirmaram que os estudantes possuem dificuldades de interpretação. Na Tabela 5 apresentam-se alguns depoimentos selecionados.

Tabela 5 - Facilidades e dificuldades dos estudantes ao resolver problemas matemáticos.

\begin{tabular}{cl}
\hline Participante & \multicolumn{1}{c}{ Depoimento } \\
\hline (1A) & $\begin{array}{l}\text { Dificuldades: compreender e interpretar o enunciado (às vezes o aluno vem com um voca- } \\
\text { bulário limitado). }\end{array}$ \\
& $\begin{array}{l}\text { Muitas vezes por ler o problema rapidamente, sem uma interpretação acabam errando a } \\
\text { (1B) }\end{array}$ \\
& $\begin{array}{l}\text { resolução. Eles amam Matemática, acham que a aula passa muito rápido, vejo que com } \\
\text { aulas práticas aprendem mais. }\end{array}$
\end{tabular}




$\begin{array}{ll}\text { (1G) } & \text { Dificuldade em fazer relação com as informações dadas e a pergunta em si. } \\ \text { (1F) } & \begin{array}{l}\text { Dificuldades: não sabem ler com calma, já desistem na primeira tentativa, não sabem qual } \\ \text { o cálculo que têm que fazer. }\end{array} \\ (1 \mathrm{H}) & \begin{array}{l}\text { Os alunos dificilmente interpretam e compreendem o problema. Não sabem que cálculo } \\ \text { utilizar, não criam estratégias de solução. }\end{array} \\ \text { (1K) } & \begin{array}{l}\text { Conhecimento das quatro operações, e as dificuldades é o pensar, pôr em prática dados já } \\ \text { estudados, concluídos (aplicabilidade). }\end{array}\end{array}$

\section{Fonte: Elaboração das autoras}

Alguns professores, $19 \%$, citaram como dificuldades o pouco estudo, a falta de concentração ou que 0 trabalho com problemas que exige mais de um algoritmo para resolução. Outros, 27\%, afirmaram que a turma possui mais facilidade do que dificuldades, como nas percepções transcritas na Tabela 6.

Tabela 6 - Mais facilidades do que dificuldades

\begin{tabular}{cl}
\hline Participante & \multicolumn{1}{c}{ Depoimento } \\
\hline (1I) & $\begin{array}{l}\text { Por ser uma turma pequena, acredito que todos conseguem resolvê-los. Se não conseguem, } \\
\text { todos se ajudam na resolução. }\end{array}$ \\
& $\begin{array}{l}\text { A maioria dos alunos consegue ler e resolver os problemas com autonomia, porém os que } \\
\text { (1C) }\end{array} \quad \begin{array}{l}\text { estão no processo de alfabetização precisam de ajuda. Alguns apresentam dificuldade em } \\
\text { saber como fazer o registro, é o caso do problema "exemplo", que alguns sabiam o resulta- } \\
\text { do mentalmente, mas não sabiam fazer a conta. }\end{array}$ \\
\hline
\end{tabular}

Fonte: Elaboração das autoras

Com efeito, conforme o professor busca refletir sobre suas inquietações pessoais, seu cotidiano na escola, a aprendizagem e 0 desenvolvimento dos seus estudantes, suas ações e práticas docentes, permite-se pensar criticamente sobre a realidade e somente assim poderá buscar formas de transformar e superar as dificuldades encontradas.

De acordo com Freire (1996, p. 38), reflexão e pesquisa são duas exigências da prática educativa. Refletir é o movimento "entre o fazer e o pensar sobre o fazer", sendo uma ação fundamental na formação permanente do professor, pois "é pensando criticamente a prática de hoje ou de ontem que se pode melhorar a próxima prática.". Segundo 0 autor, à medida que o professor reflete e torna esta, uma ação-parte de sua prática, maiores são as possibilidades de mudança; em suas palavras: "quanto mais me assumo como estou sendo e percebo a ou as razões de ser de porque estou sendo assim, mais me torno capaz de mudar, de promover-me [...]" (FREIRE, 1996, p. 39).

Todos os participantes relataram mudanças na forma como abordavam problemas matemáticos nas aulas. Estas modificações, na prática pedagógica, são frutos, também, das reflexões e ações desenvolvidas na formação continuada, que teve como estratégias, durante os encontros, a leitura e discussão de textos, aplicação de desafios e problemas matemáticos, construção de planejamentos coletivos para futura aplicação com seus estudantes. Tais ações despertaram nos participantes a necessidade da reflexão sobre qual problema matemático selecionar, o objetivo, a atenção ao enunciado e ao vocabulário, bem como o olhar sensível quanto aos erros e acertos.

Aplicar problemas matemáticos para os estudantes resolverem deixou de ser algo mecânico, sem 0 devido planejamento das ações pedagógicas necessárias para tanto. A formação continuada permitiu pensar no recurso aplicado com os estudantes, tornando o professor mais crítico sobre sua 
prática e sobre os materiais selecionados, conforme se pode constatar em reflexões como as que se apresentam na Tabela 7.

Tabela 7 - Sobre a aplicação de problemas matemáticos

\begin{tabular}{cl}
\hline Participante & \multicolumn{1}{c}{ Depoimento } \\
\hline (6A) & $\begin{array}{l}\text { Procuro analisar melhor os problemas antes de aplicá-los. Também procuro observar a } \\
\text { quantidade, pois percebi que não é a quantidade que vai fazer com que } 0 \text { aluno aprenda. }\end{array}$ \\
$(6 \mathrm{H})$ & $\begin{array}{l}\text { Ao planejar certas situações-problema, levo em consideração as discussões em grupo, as } \\
\text { leituras realizadas e a realidade dos alunos. }\end{array}$ \\
$(6 \mathrm{~J})$ & $\begin{array}{l}\text { Na medida que busquei trabalhar mais com o raciocínio, utilizando problemas que fazem } \\
\text { pensar mais e verificando o pensamento do aluno. }\end{array}$ \\
(6K) & $\begin{array}{l}\text { A mudança foi dar menos conteúdos e explorar bem cada atividade dada, fazendo-os } \\
\text { participar, argumentar, pensar em cada resposta dada. }\end{array}$ \\
\hline
\end{tabular}

Fonte: Elaboração das autoras

As reflexões realizadas, durante a formação continuada, oportunizaram aos participantes elencarem diferentes estratégias para aplicação de problemas matemáticos em sala de aula, ações pedagógicas que estavam esquecidas ou que ainda não haviam sido colocadas nos respectivos planejamentos, tais como: leitura coletiva, utilização de materiais online, uso de desenhos e desafios, questionamentos orais, abordagem de fatos concretos e/ou do dia a dia, dentre outros. Ao selecionar problemas matemáticos e refletir sobre suas escolhas, após a aplicação da atividade com os estudantes, os participantes identificaram e destacaram tópicos importantes a serem considerados ao selecionar os problemas, como mostra a Tabela 8.

Tabela 8 - Sobre a seleção dos problemas

\begin{tabular}{cl}
\hline Participante & \multicolumn{1}{c}{ Depoimento } \\
\hline$(6 \mathrm{~A})$ & Que eles estejam adequados ao nível de aprendizado, com linguagem adequada. \\
$(6 \mathrm{~B})$ & Que eles sejam coerentes, que respeitem graus de dificuldade, que favorecem a construção \\
do raciocinio matemático.
\end{tabular}

Fonte: Elaboração das autoras

Todos os participantes percebem a relevância da resolução de problemas no ensino de Matemática. Justificam que 0 estudante se torna mais reflexivo, contribuindo para que a construção de hipóteses, a concentração, a atenção, a interpretação e o raciocínio sejam estimulados. A partir da utilização da resolução de problemas, acreditam que a Matemática deixa de ser algo separado da realidade, sendo mais facilmente percebida a sua presença no dia a dia, mais prazerosa e, consequentemente, com maior potencial de motivação. Para os estudantes, os problemas matemáticos são como 
desafios e propiciam, ainda, maior interação com colegas, conforme afirmaram os professores.

Indagados a refletir se houve (ou não) mudanças em suas abordagens, na resolução de problemas com a participação na formação, $72 \%$ dos participantes afirmaram que sim, 9\% acreditam que ainda era muito recente para perceber alterações, $9 \%$ notaram algumas mudanças, e os demais não responderam. Alguns depoimentos foram selecionados e apresentados na Tabela 9.

Tabela 9 - Abordagens dos problemas, como resultado da formação

\begin{tabular}{cl}
\hline Participante & \multicolumn{1}{c}{ Depoimento } \\
\hline (6B) & $\begin{array}{l}\text { Antes um ato mais mecânico. Hoje uma análise, respeitando o processo de interpretação e } \\
\text { compreensão. }\end{array}$ \\
(6G) & $\begin{array}{l}\text { Principalmente na seleção dos problemas, na execução (questionamentos) e a avaliar não } \\
\text { só resultado final, mas o processo. }\end{array}$ \\
(6H) & $\begin{array}{l}\text { Através da formação, podemos reciclar nossos conhecimentos e melhorar a forma de } \\
\text { trabalhar com nossos alunos, assim sem dúvida houve uma mudança. }\end{array}$ \\
$(6 \mathrm{~J})$ & $\begin{array}{l}\text { Passei a escolher com mais critérios os tipos de problemas e a observar mais o raciocínio } \\
\text { do aluno para ajudá-lo. }\end{array}$ \\
(6I) & A formação amplia os horizontes, fazendo com que veja a Matemática de forma diferente. \\
\hline
\end{tabular}
Fonte: Elaboração das autoras

Os docentes expressaram que as mudanças desencadeadas estão relacionadas à utilização de diferentes estratégias, para que os estudantes resolvam problemas matemáticos e, ainda, distintos tipos de problemas são selecionados para aplicação, desafiando-os mais e fazendo uso da realidade.

A pesquisa complementa a reflexão, no sentido de superar a ação pedagógica desenvolvida, qualificando-a. "Enquanto ensino continuo buscando e procurando. Ensino porque busco, porque indaguei, porque indago e me indago. Pesquiso para constatar, constatando, intervenho, intervindo educo e me educo. Pesquiso para conhecer o que ainda não conheço [...]" (FREIRE, 1996, p. 29).

Fala-se hoje, com insistência, no professor pesquisador. No meu entender 0 que há de pesquisador no professor não é uma qualidade ou uma forma de ser ou de atuar que se acrescente à de ensinar. Faz parte da natureza da prática docente a indagação, a busca, a pesquisa. 0 que se precisa é que, em sua formação permanente, o professor se perceba e se assuma, porque professor, como pesquisador. (FREIRE, 1996, p. 29).

Segundo Garcia (2011), ao interrogar a sua própria prática, examinando-a, problematizando-a e não aceitando a realidade cotidiana escolar, o professor pode estar dando o primeiro passo para 0 processo de melhoria no ensino. Para a autora, a prática pedagógico-reflexiva pode ser segmentada em três ciclos: "reflexão prévia, reflexão durante e reflexão após a ação."

A reflexão prévia corresponde aos estudos prévios do problema - o que, como e porque ensinar tal conteúdo ou habilidade - e envolve formulação de hipóteses, busca de recursos didáticos e planejamento. A reflexão na ação desenvolve-se quando 0 professor vai ao encontro do aluno, implementando sua proposta didática. Durante esse processo, o professor pode reformular suas ações, levantar e testar novas hipóteses. Posteriormente, o professor realiza uma reflexão sobre a ação, analisando, avaliando, tentando compreender e reconstruir sua prática, para modificar, mudar rumos e planejar as próximas ações. (GARCIA, 2011, p. 19). 
Para a mesma autora, a reflexão começou a ser considerada indissociável do trabalho e da formação do professor a partir da década de 90 . Algo semelhante aconteceu com o princípio da pesquisa, segundo o qual, o professor visto como pesquisador é "aquele que explicita as inquietudes que emergem da sua prática e as toma como problema de pesquisa, procurando soluções, bem fundamentadas, com o objetivo de propor e implementar mudanças concretas na sala de aula e/ou na instituição." As ações de refletir e pesquisar tornaram-se, então, parte da ação pedagógica. Entende-se, pois, que o professor pesquisador é também reflexivo, ao tomar sua prática pedagógica como objeto de reflexão e "buscar subsídios que ajudem a compreender e a enfrentar os problemas e os desafios do trabalho docente; a reflexão reveste-se de caráter sistêmico e vale-se de contribuições teóricas que permitem ultrapassar as interpretações e soluções baseadas exclusivamente no senso comum". (GARCIA, 2011, p. 20)

\section{Categoria 3: Ensinando a resolver problemas}

Resolver problemas é uma ação essencial do ensino de Matemática, conforme afirma Pozo (1998); porém, 0 autor atenta que, "na maioria das ocasiões o ensino de Matemática tem se baseado mais na solução de exercícios de caráter sintático do que de verdadeiros problemas matemáticos." (POZO, 1998, p. 63).

Os professores que participaram da formação foram incentivados a justificar a importância da resolução de problemas. Todos os docentes apontaram sua relevância para o processo de aprendizagem; em suas percepções, a resolução de problemas matemáticos auxilia no desenvolvimento do raciocínio, na construção de hipóteses, na leitura e interpretação, na cooperação entre colegas na turma, na percepção da realidade cotidiana, na atenção e concentração e, ainda, instiga a busca por solução, desafiando 0 aluno. Na Tabela 10 são apresentadas as palavras de alguns participantes, com percepções sobre a resolução de problemas.

Tabela 10 - A resolução de problemas matemáticos

\begin{tabular}{cl}
\hline Participante & \multicolumn{1}{c}{ Depoimento } \\
\hline$(6 \mathrm{~A})$ & Faz o aluno pensar, ser mais reflexivo. \\
$(6 \mathrm{G})$ & $\begin{array}{l}\text { Acredito que seja a forma mais real e verdadeira de aproximar a Matemática com o dia a } \\
\text { dia. }\end{array}$ \\
(6J) & $\begin{array}{l}\text { Com os problemas matemáticos, é possível aplicar os conteúdos trabalhados de uma } \\
\text { forma mais prazerosa e dentro das questões cotidianas. }\end{array}$ \\
(6F) & Tudo na vida é pensar estratégias para resolver problemas. \\
\hline &
\end{tabular}

Fonte: Elaboração das autoras

Os professores elencaram diversos objetivos possíveis de serem atingidos, através da resolução de problemas matemáticos em sala de aula, tais como: desenvolver a leitura (atenção/concentração), a interpretação e a compreensão, a organização de ideias, o raciocínio lógico, a criação de estratégias e argumentos, a pesquisa e ainda a possibilidade de utilizar a realidade cotidiana dos estudantes, possibilitando-lhes serem mais autônomos em suas aprendizagens.

Com efeito, para Pozo, os problemas matemáticos são, ao mesmo tempo, um método de aprendizagem e um objetivo. Para o autor, é um método de aprendizagem porque o currículo escolar da Matemática prevê o desenvolvimento de habilidades, técnicas, algoritmos e procedimentos que 
podem ser inseridos em diferentes contextos (cotidiano, científico, etc.), e para atingir uma aprendizagem significativa faz-se necessário o uso de problemas matemáticos no contexto de sala de aula. 0 autor compreende a resolução de problemas também como um objetivo do ensino de Matemática, visto que "não é possível aprender a solucionar problemas independentemente da aprendizagem de conceitos e conhecimentos de Matemática." (POZO, 1998, p. 53).

Ainda, na BNCC, encontra-se:

Os processos matemáticos de resolução de problemas, de investigação, de desenvolvimento de projetos e da modelagem podem ser citados como formas privilegiadas da atividade matemática, motivo pelo qual são, ao mesmo tempo, objeto e estratégia para a aprendizagem ao longo de todo 0 Ensino Fundamental. Esses processos de aprendizagem são potencialmente ricos para 0 desenvolvimento de competências fundamentais [...]. (BRASIL, 2017)

Entende-se, pois, que é evidente o potencial da resolução de problemas em sala de aula, como uma metodologia para o ensino de Matemática e, diante disso, surge a curiosidade de conhecer a frequência com a qual os professores proporcionam esta atividade aos estudantes. As respostas foram distintas, sendo que $23 \%$ utilizam pelo menos uma vez por semana, $8 \%$ aplicam três vezes na semana, $8 \%$ com a frequência semanal e outros $8 \%$ quinzenalmente; pelo menos, a cada dez dias, $15 \%$ fazem uso, $15 \%$ proporcionam diariamente a atividade, $8 \%$ afirmaram não trabalhar com essa atividade e $15 \%$ não se manifestaram.

Como professores, sabe-se da importância da resolução de problemas na sala de aula, nos processos de ensino e de aprendizagem de Matemática, mas cabe refletir sobre o motivo de ainda se utilizar esta metodologia com pouca frequência. De fato, esta afirmação foi comprovada, pelos participantes do curso, que expressaram suas opiniões, algumas delas, transcritas na Tabela 11.

Tabela 11 - Frequência da utilização da resolução de problemas

\begin{tabular}{cl}
\hline Participante & Depoimento \\
\hline (3B) & Utilizo mais exercícios. Proponho problemas em média uma vez por semana. \\
$(3 \mathrm{E})$ & $\begin{array}{l}\text { Muitas vezes proponho mais exercícios de fixação, quando o meu objetivo é que eles saibam } \\
\text { um determinado conteúdo. }\end{array}$ \\
$(3 \mathrm{~F})$ & $\begin{array}{l}\text { Acredito que proponho mais exercícios, pois os problemas trabalhados acabam tendo ca- } \\
\text { racterísticas de exercícios. }\end{array}$ \\
(3K) & Depende do objetivo, quando quero que fixem o conteúdo proponho mais exercícios. \\
\hline
\end{tabular}

Fonte: Elaboração das autoras

Nesta ocasião julgou-se oportuno comentar sobre a distinção entre exercício e problema. Para a maioria dos participantes, exercício é entendido como uma atividade de fixação, repetição, ação mecânica e que não exige reflexão durante a busca pelo resultado; é simplesmente a aplicação de regras. Já o problema requer que 0 estudante desenvolva a leitura (concentração), o raciocínio, a compreensão e a interpretação, para depois realizar o algoritmo e chegar a uma resolução. 0 problema é mais desafiador e mobiliza habilidades e conhecimentos. É contextualizado, pode utilizar-se de uma situação real (necessidade) e requer reflexão, mobiliza diversos conhecimentos e habilidades. 
De fato, tais concepções estão em consonância com as ideias de Pozo, já que para o autor,

a realização de exercícios se baseia no uso de habilidades ou técnicas sobreaprendidas, (ou seja, transformadas em rotinas automatizadas como consequência de uma prática contínua). Limitamo-nos a exercitar uma técnica quando enfrentamos situações ou tarefas já conhecidas, que não representam nada de novo e que, portanto, podem ser resolvidas pelos caminhos ou meios habituais (POZO, 1998, p. 16, grifo do autor).

Conforme este autor "um problema é, de certa forma, uma situação nova ou diferente do que já foi aprendido, que requer a utilização estratégica de técnicas já conhecidas".

[...] uma situação somente pode ser concebida como um problema na medida em que exista um reconhecimento dela como tal, e na medida em que não dispomos de procedimentos automáticos que nos permitam solucioná-la de forma mais ou menos imediata, sem exigir, de alguma forma, um processo de reflexão ou uma tomada de decisões sobre a sequência de passos a serem seguidos. (POZO, 1998, p. 17).

Fica evidente a distinção entre exercício e problema: "um problema se diferencia de um exercício na medida em que, neste último caso, dispomos e utilizamos mecanismos que nos levam, de forma imediata, à solução." (POZO, 1998, p. 17). Os participantes foram requisitados a explicitar a diferença entre exercício e problema e, conforme se observou, de fato, 17\% afirmaram que até o momento anterior à formação não haviam refletido sobre a distinção, conforme depoimentos, transcritos na Tabela 12.

Tabela 12 - Diferença entre exercício e problema

\begin{tabular}{cl}
\hline Participante & \multicolumn{1}{c}{ Depoimento } \\
\hline (3D) & $\begin{array}{l}\text { Não havia pensado na diferença entre exercício e problema. Mas após o estudo feito, en- } \\
\text { tendi que é necessário realizar o exercício para compreender a operação, após se contex- } \\
\text { tualizar dentro de um problema as operações. }\end{array}$ \\
& $\begin{array}{l}\text { Infelizmente não havia pensado, porém, através das leituras e discussões com colegas, } \\
\text { percebi que cada um tem a sua particularidade, um é apenas prática, exercitar (EXERCícI0) } \\
\text { (3F) o outro é pensar, raciocinar. Caímos no erro de acreditar que estamos proporcionando } \\
\text { problemas para os alunos, porém, exercícios meramente. }\end{array}$ \\
\hline
\end{tabular}

\section{Fonte: Elaboração das autoras}

Através das falas dos professores, foi possível perceber também esta contribuição da formação continuada desenvolvida. Os demais participantes, $83 \%$, conheciam a diferença entre exercício e problema e, em suas falas, demonstram compreender 0 sentido de ambos, aproximando suas definições do conceito supracitado e definido por Pozo, que complementa:

[...] não é possível determinar, em geral, se uma tarefa escolar determinada é um exercício ou um problema; isto depende não somente da experiência e dos conhecimentos prévios de quem a executa, mas também dos objetivos que estabelece enquanto a realiza. Quando a prática nos proporcionar a solução direta e eficaz para 
a solução de um problema, escolar ou pessoal, acabaremos aplicando essa solução rotineiramente, e a tarefa servirá, simplesmente, para exercitar habilidades já adquiridas. (POZO, 1998, p. 17).

Em muitas falas, durante a formação continuada, os professores indicaram as dificuldades dos estudantes em compreenderem problemas matemáticos. Para Pozo (1998) a compreensão de um problema matemático é influenciada por muitos fatores, como: 0 conteúdo, a relação com os conhecimentos já construídos pelo aluno, o contexto e a linguagem. Na Tabela 13 são apresentados depoimentos de professores, relacionados a dificuldades dos estudantes na resolução de problemas.

Tabela 13 - Dificuldades na resolução de problemas

\begin{tabular}{cl}
\hline Participante & \multicolumn{1}{c}{ Depoimento } \\
\hline (3A) & $\begin{array}{l}\text { Percebo que, apesar da frequência com que proporciono situações-problema eles continuam } \\
\text { evidenciando dificuldades de entendimento e resolução. }\end{array}$ \\
& $\begin{array}{l}\text { Eu esperava que eles compreendessem o que deveria ser feito em cada problema, indepen- } \\
\text { dente de acertar ou errar a conta em si, mas a dificuldade maior era entender o que fazer } \\
\text { em cada problema. }\end{array}$ \\
\hline
\end{tabular}

Fonte: Elaboração das autoras

Para Pozo não existem materiais que ajudem diretamente os alunos a resolverem problemas, mas 0 que existem são algumas técnicas que podem ajudar os alunos a compreenderem e traduzirem um problema para o concreto. Não há milagres a serem feitos pelo professor, "a solução de problemas dentro de uma área do conhecimento concreta é aprendida resolvendo-se problemas dentro dessa área." [...] E propõe "algumas técnicas que ajudam a compreender melhor os problemas matemáticos", quais sejam:

Expressar o problema com outras palavras.

Explicar aos colegas em que consiste o problema.

Representar o problema com outro formato (gráficos, diagramas, desenhos, com objetos, etc.).

Indicar qual é a meta do problema.

Apontar onde reside a dificuldade da tarefa.

Separar os dados relevantes dos não relevantes.

Indicar os dados com os quais contamos para resolver a tarefa.

Indicar quais os dados que não estão presentes mas que são necessários para resolver a tarefa.

Procurar um problema semelhante que já tenhamos resolvido.

Analisar inicialmente alguns exemplos concretos, quando o problema é muito geral.

Procurar diferentes situações (cenários, contextos, tarefas, etc.) nas quais esse problema possa ter lugar. (POZO, 1998, p. 59).

Segundo os professores, ao se propor atividades de resolução de problemas, diferentes estratégias podem ser utilizadas com os estudantes, para auxiliar na compreensão, conforme evidenciaram em suas falas, algumas das quais, apresentadas na Tabela 14. 
Tabela 14 - Estratégias que auxiliam na resolução de problemas

\begin{tabular}{cl}
\hline Participante & \multicolumn{1}{c}{ Depoimento } \\
\hline (1A) & Às vezes é possível utilizar material concreto, através de desenhos, dramatizações. \\
(1C) & Leitura individual, leitura coletiva, dou dicas depois de um tempo para resolverem e depois \\
(1E) & a correção coletiva. \\
\hline
\end{tabular}

Fonte: Elaboração das autoras

Pode-se perceber que as técnicas indicadas por Pozo não são exatamente iguais às utilizadas pelos professores, pois, como sabemos, 0 ato pedagógico se faz através de adaptações que seguem a realidade escolar da turma. Conforme também indica Pozo (1998, p. 59), "a direção exercida pelo professor, no que se refere a esse processo de reflexão, com técnicas ou com outros recursos similares, deve variar em função das características dos próprios alunos".

0 mesmo autor justifica a utilização das técnicas para a tradução ou compreensão do problema como forma de instigar o aluno a refletir antes de agir, planejando o processo de resolução. "As pessoas iniciantes (os alunos, no nosso caso) têm muito pouca consciência dos meios com os quais contam para resolver uma tarefa. Por outro lado, como víamos antes, normalmente tendem a resolver as tarefas de forma imediata, sem um período de reflexão prévia." (POZO, 1998, p. 59).

\section{Categoria 4: Contribuições da formação continuada na prática pedagógica}

Os participantes foram convidados a analisar a formação continuada que cursaram, respondendo um questionário contendo perguntas abertas. Registraram suas reflexões de forma anônima. Esta atividade foi realizada no último encontro do curso.

Questionados se a formação havia atingido suas expectativas sobre o tema resolução de problemas matemáticos, $91 \%$ dos participantes afirmaram que sim, e $9 \%$ dos participantes indicaram que 0 curso atendeu em parte, porém não justificaram o que deixou a desejar. Algumas considerações dos participantes são apresentadas na Tabela 15.

Tabela 15 - Análise da formação continuada promovida: aspectos positivos

Participante
(6B)
$\begin{aligned} & \text { A formação contemplou e atingiu além das minhas expectativas pessoais. Veio ao encontro } \\ & \text { das minhas necessidades, enquanto profissional docente. [...] Condução segura da formação, } \\ & \text { indo ao real encontro das nossas necessidades. }\end{aligned}$
Fez-me repensar o ensino de Matemática, como diversificar atividades envolvendo os
cálculos no nosso dia a dia.[...]Diversidade de atividades. Orientação e explicações feitas
com clareza. Sites para pesquisar.
Já estou utilizando. Refletir diante de cada proposta antes de "aplicá-la", avaliar o proces-
so e os resultados são algumas estratégias já agregadas no fazer pedagógico. [...]
Especialmente a troca entre colegas: "faço isso", "já fiz isso", "não deu certo quando".
Acho que isso foi muito importante.[...] O grupo pequeno contribuiu para interação de
todos. Organização. Conteúdos abordados.




A cada noite de curso saio com muitas ideias e sugestões que pretendo aplicar com meus alu-
nos (algumas já apliquei).[..] Foi muito proveitosa, apesar de pertencermos à mesma rede de
ensino, estes momentos podemos trocar experiências e enriquecer o trabalho com os alunos.
[6I)...] Didática da professora. Grupo. Trabalhos práticos. Aulas diferenciadas. Troca de ideias.
Auxiliou no "sair" da mesmice para um fazer mais dinâmico.[...] Aulas práticas. Uso de
tecnologias. Conteúdo de fácil entendimento.
(6A) $\quad$ Novas ideias. Adorei os jogos.
(6C) $\quad$ Segurança na condução do curso. Contribuição significativa para a sala de aula.
(6D) $\quad$ do convolvimento que o grupo teve e participação junto da professora para aperfeiçoamento dos professores.
(6E) $\quad$ Envolvimento do grupo. Troca de experiências e ideias. Relatos das turmas.
(6F) $\quad$ Materiais diversificados. Jogos. Reflexão.
(6J)

\section{Fonte: Elaboração das autoras}

Quanto aos aspectos a melhorar, $81 \%$ dos participantes nada indicaram ou afirmaram estar satisfeitos com a formação cursada. Os demais 19\% indicaram aspectos a serem melhorados, como se pode observar nos relatos apresentados na Tabela 16.

Tabela 16 - Análise da formação continuada promovida: aspectos a serem melhorados

\begin{tabular}{cl}
\hline Participante & \multicolumn{1}{c}{ Depoimento } \\
\hline$(6 \mathrm{~A})$ & $\begin{array}{l}\text { Poderíamos ter aproveitado melhor o tempo. Em alguns momentos poderíamos ter visto } \\
\text { mais coisas. }\end{array}$ \\
\hline$(6 \mathrm{~K})$ & Curso de 2h por vez. Duração de mais tempo de curso. \\
\hline
\end{tabular}

Fonte: Elaboração das autoras

Apenas um participante contribuiu com ideias para a qualificação da formação, sugerindo que fosse desenvolvida para cada ano escolar específico, separando os professores em turmas de $1^{\circ}$ ao $5^{\circ}$ ano, de acordo com o nível em que atuam; $82 \%$ dos participantes demonstraram interesse em continuar qualificando sua trajetória profissional, através de outras formações, e afirmaram ainda que gostariam de uma continuidade na formação cursada. Na Tabela 17 são apresentadas sugestões dos participantes.

Tabela 17 - Sugestões para continuidade

\begin{tabular}{cl}
\hline Participante & \multicolumn{1}{c}{ Depoimento } \\
\hline$(6 \mathrm{~B})$ & Que haja outros cursos de formação com esta conotação. \\
$(6 \mathrm{C})$ & Que haja uma continuidade do curso no próximo ano. \\
$(6 \mathrm{D})$ & Que todos os anos tenha um curso à altura deste. \\
$(6 \mathrm{~F})$ & Fazer a segunda edição. \\
$(6 \mathrm{G})$ & Continuação no próximo ano! \\
$(6 \mathrm{H})$ & Novo curso no início ou meio do ano. \\
$(6 \mathrm{I})$ & A ll etapa do curso seria maravilhoso. \\
\hline$(6 \mathrm{~K})$ & No próximo ano continuar o curso de Matemática com a mesma Profa ${ }^{\text {Morgana. }}$ \\
\hline
\end{tabular}

Fonte: Elaboração das autoras 
Percebeu-se que a formação realizada foi significativa, sendo assim reconhecida pelos professores que participaram do curso, pois viabilizou a reestruturação das práticas pedagógicas, e permitiu qualificar o ensino e a aprendizagem de Matemática, nos anos iniciais do Ensino Fundamental, fazendo uso da resolução de problemas, aproximando a Matemática do cotidiano do estudante, por meio dos recursos apresentados, das reflexões desencadeadas e das interações com os colegas professores da mesma rede de ensino. Pode-se afirmar que a formação continuada propiciou mudanças na abordagem dos problemas matemáticos em sala de aula, pois os professores demonstraram maior preocupação ao planejar, considerando a importância de explicitar objetivos e recursos pedagógicos utilizados, assim como da atenção ao avaliar, analisando os erros e os acertos dos estudantes.

\section{CONSIDERAÇÕES FINAIS}

A concepção de educação não deve considerar apenas o desenvolvimento dos conteúdos científicos, mas a formação integral do ser humano. Assim, a presente pesquisa tornou-se uma opção para qualificar a aprendizagem dos estudantes, através da formação continuada, em que os professores puderam refletir e qualificar a prática pedagógica, visando contribuir significativamente no ensino escolar.

A formação continuada desenvolvida oportunizou aos professores a reflexão sobre o processo educativo, em especial sobre as práticas relacionadas ao ensino de Matemática. Os sujeitos da pesquisa, professoras e formadora, trabalharam em conjunto, planejando e avaliando formas de qualificar a prática desenvolvida em Matemática, utilizando a resolução de problemas. Só é possível um ensino com qualidade com professores preparados e que buscam aperfeiçoamento constante.

Retomando a questão principal da pesquisa: Qual a contribuição de um curso de formação continuada, com enfoque na resolução de problemas matemáticos, para a prática pedagógica do professor dos anos iniciais do Ensino Fundamental?, concluiu-se que uma das primeiras contribuições foi o modo como a formação foi desenvolvida, pois propiciou mudanças na prática pedagógica, desencadeadas pelas constantes reflexões e ações, unindo teoria e prática e realizando novas experiências didáticas.

De fato, foi possível constatar que a formação continuada realizada atingiu as expectativas de grande parte dos professores, sendo que as estratégias pedagógicas discutidas nos encontros, foram percebidas como possíveis de serem aplicadas em sala de aula, para qualificar o trabalho pedagógico e a aprendizagem da Matemática. Analisando as manifestações dos participantes ao avaliarem a formação continuada, pôde-se perceber o impacto positivo que a mesma teve na prática pedagógica, pois muitos professores refletiram e alteraram suas ações em sala de aula, utilizando a resolução de problemas matemáticos como meio para promover aprendizagem, e não apenas como mera atividade de sala de aula, sem um objetivo a ser atingido.

Além disso, os participantes relataram mudanças na abordagem dos problemas matemáticos em sala de aula e na escolha de recursos adequados; houve maior preocupação com o objetivo de cada atividade, com maior atenção ao vocabulário (enunciado) e com a análise dos erros e dos acertos dos estudantes. A resolução de problemas matemáticos em sala de aula passou a ser proposta como algo desafiador para o estudante, mas também para os professores participantes. Todos sinalizaram que pretendem utilizar as estratégias pedagógicas discutidas na formação, pois as percebem como forma de qualificar os processos de ensino e de aprendizagem, sendo que $45 \%$ dos professores sinalizaram já estar fazendo uso em seu planejamento. 
Os professores que complementaram as aulas com as atividades de formação, indicaram estar utilizando os jogos (concretos e virtuais) e os desafios na sala de aula, além de diversificar os problemas matemáticos propostos aos estudantes. Também as trocas entre colegas do grupo foram destacadas como positivas e enriquecedoras.

Espera-se, pois, que os resultados aqui discutidos possibilitem a outros educadores repensarem suas ações pedagógicas, contribuindo assim para os processos de ensino e de aprendizagem de Matemática, especialmente nos primeiros anos do Ensino Fundamental.

\section{REFERÊNCIAS}

BOZZA, M. Formação Continuada de Professores: contribuições da resolução de problemas matemáticos nos anos iniciais do ensino fundamental. 2017. 181 f. Dissertação (Mestrado Profissional em Ensino de Ciências e Matemática) - Programa de Pós-Graduação em Ensino de Ciências e Matemática, Universidade de Caxias do Sul, 2017. Disponível em: https://bit.ly/38ikmza. Acesso em: 26 mai. 2020.

BRASIL. Base Nacional Comum Curricular (BNCC). Educação é a Base. Brasília, MEC/CONSED/UNDIME, 2017. Disponível em: http://basenacionalcomum.mec.gov.br/abase/\#fundamental/a-area-de-matematica. Acesso em: 12 abr. 2020.

CHIMENTÃO, L. K. 0 significado da formação continuada docente. In:CONGRESSO NORTE PARANAENSE DE EDUCAÇÃO FÍSICA ESCOLAR - CONPEC, 4., Paraná, 2009. Anais... Disponível em: https://bit.ly/2GCcLAg. Acesso em: 5 fev. 2020.

DAMAZI0, A. Formação continuada do professor de matemática: produções pessoais. Poiésis, Tubarão, v. 1, n. 1, p. 07-19, 2008.

FIORENTINI, D.; LORENZATO, S. Investigação em Educação Matemática. Campinas: Autores Associados, 2009.

FREIRE, P. Pedagogia da autonomia: saberes necessários à prática educativa. 37.ed. São Paulo: Paz e Terra, 1996.

GARCIA, V. C. V. (Org.). Reflexão e pesquisa na formação de professores de matemática. Porto Alegre: Evangraf, 2011.

GODOY, E. V.; SANTOS, V. M. 0 cenário do ensino de Matemática e 0 debate sobre 0 currículo de Matemática. Práxis Educacional, Vitória da Conquista, v. 8, n. 13, p. 253-280, 2012.

KÖNIG, R. I. Resolução de problemas matemáticos na formação continuada de professores. 2013. $271 \mathrm{f}$. Dissertação (Mestrado Profissional em Ensino de Ciêncas Exatas) - Programa de Pós-Graduação do Centro Universitário Univates, Lajeado, 2013. Disponível em: https://bit.ly/21756dl. Acesso em: 26 out. 2020.

LIMA, I. M. S.; SILVA NETO, J. F.. 0 que pensam professores que ensinam matemática na educação básica sobre a formação continuada? Pesquiseduca, v. 4, n. 7, p. 06-23, 2012.

MORAES, R. Análise de conteúdo. Revista Educação, Porto Alegre, v. 22, n. 37, p. 7-32, 1999. Disponível em: https:// bit.ly/2lboKVG. Acesso em: 4 jan. 2020. 
PACHECO, M. B.; ANDREIS, G. S. L. Causas das dificuldades de aprendizagem em Matemática: percepção de professores e estudantes do $3^{0}$ ano do Ensino Médio. Revista Principia - Divulgação Científica e Tecnológica do IFPB, [S.I.], n. 38, p. 105-119, fev. 2018. ISSN 2447-9187. Disponível em: https://bit.ly/3n2x3SP. Acesso em: 20 out. 2020.

POZO, J. I. A solução de problemas: aprender a resolver, resolver para aprender. Porto Alegre: Artmed, 1998.

SILVA, J. C. M. Formação continuada dos professores: visando a própria experiência para uma nova perspectiva. Revista Ibero-Americana de Educação. 2011. Disponível em: https://bit.ly/2GzAQHZ. Acesso em: 5 abr. 2020.

RECEBID0 EM: 30 jun. 2020

CONCLUÍDO EM: 25 out. 2020 
